Biosystems Engineering, Volume 84, Issue 4, April 2003, Pages 425-440

\title{
Soil Factors and their Influence on Within-Field Crop Variability I: Field Observation of Soil Variation
}

R. Earl ${ }^{1}$; J.C. Taylor ${ }^{1}$; G.A. Wood ${ }^{1}$; I. Bradley, I.T. James ${ }^{1}$, T. Waine ${ }^{1}$; J.P. Welsh ${ }^{1}$; R.J. Godwin ${ }^{1}$ S.M. Knight ${ }^{2}$

${ }^{1}$ Cranfield University at Silsoe, Silsoe, Bedfordshire MK45 4DT, UK; e-mail of corresponding author: $\underline{\text { r.earl@cranfield.ac.uk }}$

${ }^{2}$ Arable Research Centres, Shuttleworth Centre, Old Warden Park, Biggleswade, Bedfordshire SG18 9EA, UK 


\section{Abstract.}

A fundamental component of adopting the concept of precision farming in practice is the ability to measure spatial variation in soil factors and assess the influence of this on crop variability in order to apply appropriate management strategies. The aim of this study was to appraise potential methods for measuring spatial variability in soil type, nutrient status and physical properties in practical farming situations. Five fields that are representative of more than $30 \%$ of soils used for arable production in England and Wales were selected for use as case studies. Maps of soil type were generated from a conventional hand auger survey on a $100 \mathrm{~m}$ grid and the excavation of targeted soil profile pits. These were compared with those refined using a mechanised soil coring device and scans of electromagnetic inductance (EMI) carried out while the soil could reasonably be considered to be at, or near, field capacity moisture content. In addition, soil sampling for nutrient analyses was conducted on a $50 \mathrm{~m}$ grid to examine the spatial variation in nutrient status. Conventional methods for sampling soil were found to be appropriate for identifying soil types at specific locations within the field sites, however, they were time-consuming to perform which placed an economic and therefore a practical limitation on the sampling density possible. The resulting data were considered to be too sparse for demarcating soil type boundaries for use in the context of precision farming. The location of soil boundaries were refined by using the mechanised soil corer, however, the limitation of this was found to be the time required to analyse the soil cores produced. Maps of soil variation generated from EMI scans conducted at field capacity appear to reflect the underlying variation in soil type observed in maps generated using the mechanised soil corer. and, therefore, this approach has potential as a cost-effective, data-rich, surrogate for measures of soil variability. Results from analyses of soil samples for measurement of nutrient status indicated that whilst there was considerable variation in macro- and micro-nutrient levels in each field, with the exception of $\mathrm{pH}$, these levels were above commonly accepted agronomic limits. Results did however demonstrate the potential for addressing variation in critical factors such as $\mathrm{pH}$ 
at specific locations, however, there is a need to develop protocols for targeting sampling in order to reduce costs.

\section{Introduction}

In the context of this work, precision farming is defined as within-field site-specific management of inputs to match crop yield potential (Earl et al., 1996). The potential benefits of this are:

(1) economic benefits of optimising crop production,

(2) risk-reduction of environmental pollution from over-application of agrochemicals, and

(3) improved traceability through precise targeting and recording of field operations.

The concept of maximising return from areas within a field is attractive to farmers. However, the achievement of this aim in practice requires a greater understanding of the variability in soil factors across fields (spatial variability) and influence on crop performance. This is needed both within a given season, and over a number of seasons (temporal variability).

This paper examines the relationship between soil and soil nutrient spatial variability and crop performance and the potential for site-specific management, in a number of fields to establish a practical number of management zones for site-specific management. The focus of Part I is on the appraisal of potential field observation methods for assessing spatial variation in soil and soil nutrients in trial fields. Part II of this paper explores the relationships between spatial variability of soil nutrients (excluding nitrogen as this is dealt with in detail in this issue by Welsh et al., 2001a \& b, and Wood et al. 2001), $\mathrm{pH}$ and soil physical factors and spatial variation in crop yield. In order to ensure that results are of relevance to farmers, a practical approach to this study was adopted which involved field scale experimentation on working farms. The research addresses the following: 


\section{Part I:}

(1) Identification of methods for measuring spatial variation in soil factors in fields.

(2) Identification of field sites that are representative of typical commercial cereal farming situations, for use as case studies.

(3) Appraisal of conventional methods for measuring spatial variation in soil factors and their potential for use in practical farming situations.

(4) Assessment of the potential of electromagnetic inductance (EMI) for use as a costeffective surrogate for measures of spatial variation in soil physical properties.

\section{Part II:}

(1) Development of appropriate sampling strategies to minimise costs whilst optimising the usefulness of data collected.

(2) Development of procedures for analysing these data to investigate relationships that may exist between soil and crop spatial variation.

(3) Development of procedures for dividing fields into management zones based on measures of spatial variation.

\section{Methods for measuring spatial variation in soil factors}

A summary of techniques potentially of use for measuring within-field variability of soil is presented in Table 1. Soil surveys based on auger sampling are commonly used to provide an indication of type, and spatial extent, of soils present in a field. Commercial surveys are typically conducted using a grid of 100 by $100 \mathrm{~m}\left(1\right.$ sample.ha $\left.{ }^{-1}\right)$ in order to produce a soil map at 1:10,000 scale. This is a compromise between achieving sufficient resolution to identify accurate boundaries between different soil types within a field, and cost. 
Profile pits are rarely used on commercial farms as they are time-consuming to excavate and assess and, due to logistical considerations, only a limited number of pits per field is practical. This limits the extent to which the data from each pit are representative of the whole field. However, a new guide to assessing soil structure and compaction (NSRI, 2001) suggests that information from a few carefully targeted soil pits is invaluable.

Minicore soil samples have become available as a result of recent developments in vehicularmounted soil coring devices and provide the opportunity to mechanise the taking of soil cores to depths of $1 \mathrm{~m}$. Minicores are extracted from the soil profile in transparent acrylic tubes, which allow rapid assessments of the soil profile and rooting depth to be made.

Electro-magnetic inductance (EMI) scanning is a rapid, non-invasive method for collecting soil electrical conductivity information. EMI responds to electrical properties of the soil which are determined by a complex interplay of soil clay content, water content, organic matter and salinity (Jaynes et al., 1994). Whilst EMI has proved useful in monitoring soil salinity (Rhoades and Corwin, 1981), where levels of salinity are relatively low, the technique also has considerable potential for measuring water content (Kachanoski et al., 1988; Waine, 1999; Waine, et al., 2000) and soil textural variation (Williams and Hoey, 1987; James et al., 2000; Dalgaard et al., 2001).

Sampling of soil for assessments of nutrients and $\mathrm{pH}$ status is common practice on commercial farms. Depending on whether uniform or variable application of nutrients is anticipated, assessments are typically conducted either by bulking samples obtained from walking a "W" across a field (MAFF, 2000), or by analysing individual soil samples taken at $100 \mathrm{~m}$ grid points. 


\subsection{Selection of experimental field sites}

Five sites were selected for this study. A summary of their attributes is presented in Table 2 .

The sites were chosen to fulfil the following criteria:

(1) To be representative of current management skills and practices in a modern farming situation.

(2) To present a variation of soil type and agronomic conditions.

(3) To have a history of monoculture in cereal production and be able to maintain that cropping system for the duration of the study.

The exception was Far Sweetbrier, which was to be conventionally farmed in a typical wheat/oilseed/beans rotation. The range of soils present at the sites is representative of a large proportion (more than 30\%) of soils used for arable production in England and Wales as shown in Fig. 1.

The practice of continuous cereal production was chosen for this project to provide uniformity and reduce the consequential effects of rotation that may not necessarily reflect management, for example differing nitrogen residues left from different crops.

\section{Soil variation at the field sites}

\subsection{Soil survey and profile pits}

The Soil Survey and Land Research Centre (SSLRC) conducted a soil survey at each of the five field sites using a $100 \mathrm{~m}$ grid (Avery, 1987). The survey was used to produce maps of soil series based on Clayden and Hollis (1984) and these are presented in Fig. 2. 
The soil maps indicated the presence of three to four different soil series in four fields, Far Sweetbrier was uniform. This information was supplemented by observations from profile pits excavated to a depth of $1.5 \mathrm{~m}$. The number and location of pits were selected to encompass:

(1) The range in yield observed in the yield map from the previous season (1 pit in high, medium and low yielding areas).

(2) The range in crop canopy density, inferred from aerial digital photography (Wood et al., 1998 and 2001), in the May preceding pit excavation in August following harvest (1 pit in a high, medium and low density area).

(3) The range of soil types observed in soil maps presented in Fig. 2.

In order to encompass the range of soil type, canopy density and yield encountered at each site, approximately nine profile pits per field were excavated and assessed. The locations of the profile pits have been superimposed onto Fig. 2. This number is greater than that required for commercial farm practice and could, from experience, be reduced to 4 to 5 pits per field. Photographs of selected soil profiles that are representative of the soil series identified from the auger survey are presented in Figs 3 to 6 and described in the following sections.

\subsubsection{Far Sweetbrier}

Seventeen observations were made across Far Sweetbrier and the adjoining field. Apart from one site with a heavy clay loam topsoil and upper subsoil, all the sites were clayey to the surface and uniform in characteristics (Figs. 3A \& 3B).

All the soils are in wetness class II (Hall et al., 1977). Hanslope series is the most extensive and best-known soil on chalky till in eastern England. The soils are distinguished by their heavy clay topsoil and the presence of a slowly permeable, slightly mottled horizon directly below the topsoil at around $300 \mathrm{~mm}$ depth. This subsoil horizon, although chalky and calcareous, is naturally 
compact and poorly structured and therefore remains wet for long periods from late autumn to early spring. Grey chalky clay is often reached within $600 \mathrm{~mm}$ of the surface. Whilst there was some evidence of compaction in the headland, this did not appear to restrict the maximum rooting depth.

\subsubsection{Onion Field.}

Nineteen observations were made across the field. Apart from two sites with a heavy clay loam topsoil and upper subsoil, all the sites were clayey to the surface. All the soils are in wetness class III (Hall et al., 1977). The predominant soil series is Evesham. These stoneless seasonally waterlogged swelling clayey soils are formed where clay is relatively free from stones (Fig. 4A).

They are calcareous to within $400 \mathrm{~mm}$ depth and often to the surface. Topsoils are very dark greyish brown and overlie a similar olive brown slightly mottled subsoil with a moderate to strong structure. With increasing depth, mottles become more common indicating prolonged periods of waterlogging. In this part of the country, Evesham soils are wetter than elsewhere, probably due to the greater than 50 percent clay throughout the profile. In summer the soils shrink on drying and cracks develop at the surface, extending deep into the subsoil. Denchworth soils are noncalcareous to at least $700 \mathrm{~mm}$ depth, stoneless and strongly mottled. The topsoil is typically a dark greyish brown clay which passes to a weaker and coarser structured subsoil (Fig. 4B). Matrix colours become greyer with depth. Structures become more distinct as the effects of shrink and swell become more pronounced. Oxpasture series comprises clay loam over clay soil in which the underlying clay is slowly permeable and as a result these soils are subject to slight seasonal waterlogging. The topsoil is a slightly stony clay loam; the immediate subsoil is a brown clay loam which overlies olive grey mottled grey calcareous clay at about $600 \mathrm{~mm}$ depth (Fig. 4C). Very fine and fine fibrous roots were found to depths in excess of $1 \mathrm{~m}$ across the site. 
Trent Field. Fifteen observations were made across the field. Apart from one site with a deep clay loam topsoil and subsoil, all the sites had chalk at 300 to $700 \mathrm{~mm}$ depth. All the soils are in wetness class I (Hall et al., 1977). Andover series comprises shallow freely draining silty clay loam over chalk (Fig. 5A). Topsoils are 250 to $350 \mathrm{~mm}$ thick, slightly or moderately stony with flint and chalk stones. Roots penetrated deeply into the underlying chalk but were restricted at pits F and $\mathrm{G}$, the former due to soil compaction in the upper horizons and the latter due to insufficient moisture in the lower horizons. Panholes series is freely draining and similar to the Andover soil, but deeper (Fig. 5B).

Topsoils are brown, stony silty clay loams with chalk and flint stones. Subsoils are similar in texture but browner in colour and overlie shattered chalk at 400 to $600 \mathrm{~mm}$ depth. The small area mapped as "disturbed" has a very deep greyish brown silty clay loam topsoil overlying a layer of mixed origin. It is understood that the soils could result from levelling of a previous hollow.

\subsubsection{Twelve Acres.}

Seventeen observations were made across the field. Apart from one site with a heavy clay loam topsoil and deep silty clay loam subsoil, all the sites were clayey to the surface, with limestone at 300 to $700 \mathrm{~mm}$ depth.

All the soils are in wetness class I. Sherborne series consist of a calcareous topsoil to between 250 and $350 \mathrm{~mm}$ depth over a thin yellowish brown subsoil that quickly passes to brashy Oolitic limestone (Fig. 6B). The textures are clayey throughout the profile. Moreton series is similar to Sherborne soils but deeper to limestone, usually 500 to $600 \mathrm{~mm}$ (Fig. 6A). The yellowish brown subsoil is moderately to very stony with small angular and platy limestone stones although roots penetrate the limestone layers (brash). Didmarton series comprises deep soil that has formed at the 
bottom of slopes and dry valley bottoms in colluvium. The profile is clayey throughout, but the clay content diminishes with depth and is well drained and stoneless to depth (Fig. 6C).

\subsubsection{Short Lane.}

There are three distinct soil types in the field. They differ in both texture and inherent soil wetness. Medium to heavy loams over stoneless clay (Wickham series) occur in the northern part of the field. These soils have slowly permeable subsoils and are seasonally waterlogged (wetness class III). In the south west and east of the field are soils of the Maplestead series - well drained (wetness class I) light loamy soils passing to sand or sandstone at less than $900 \mathrm{~mm}$ depth. The areas between the Maplestead and Wickham soils are typified by medium loamy soils of the Ludford and series, that show some evidence of seasonal waterlogging below $600 \mathrm{~mm}$ depth (wetness class II) caused by a fluctuating water table above deep clay.

\subsection{Mechanised minicore survey}

Cores were extracted from Trent Field, Twelve Acres and Short Lane as part of a parallel study by Lark et al. (1998). Between 50 and 180 cores were extracted from each field depending on field size and degree of variability in the spatial distribution of differing soil types observed in the soil maps. Observations of the resultant cores were used to refine the location of the soil type boundaries established during the hand-auger survey and these are presented in map form in Fig. 7.

A comparison between the soil maps generated from the hand auger survey and those refined through increased sampling density using the mechanised soil corer (Figs 2 and 7) reveal that there is generally good agreement between the two. However, in Trent Field, the area classified as Panholes series was found to cover a larger area in the south of the field than first thought, in Twelve Acres a fourth soil series (a deeper version of Moreton named Haselor) was identified, and 
in Short Lane the Maplestead series was found to extend over a much wider area than previously detected.

\section{Comparison of soil sampling methods for determining soil series}

Methods for providing soil samples for assessment were examined. Whilst all three methods enable observations of soil to be made, they each have a number of disadvantages associated with them. Hand augering and the excavation of profile pits are very time-consuming and this limits the number of observations possible from both an economic and practical perspective. Although both methods provide information that can lead to the identification of soil features prevailing at specific locations within a field, data sets comprising a number of observations are generally too sparse for identifying close-spaced spatial variation in soil characteristics across that field.

Mechanised soil coring devices are capable of providing soil samples from across a field at sufficiently high sampling density to enable accurate boundaries demarcating changes in soil type to be located. However, analysis of the soil cores produced is time-consuming and this therefore limits the sampling density that is practical. In addition, all three methods require a certain degree of expertise in the interpretation of the soil observed.

In order to determine the spatial variability in soil type across a field, and remain within financial and practical constraints, there is a need for methods that are capable of providing a high density of observations and interpretations but at low cost. An approach that has potential as a basis for fulfilling these requirements is the use of electromagnetic induction (EMI) as a surrogate for measures of soil physical properties. 


\section{Measurement of variation in electromagnetic induction}

In order to optimise the use of EMI data, it is important that a protocol for carrying out the scanning operation is adopted that assists the interpretation of the EMI data in terms of isolating soil factors of interest. A major influence on crop performance during the growing season is the soil water status. Water logging of cereals can have long term detrimental effects after only nine days (Cannell et al., 1978). Conversely, as soil dries, the development of soil moisture tension beyond critical limits for a plant also compromises the ultimate performance of the crop. For soils in the United Kingdom, if the moisture status at field capacity (FC) and permanent wilting point (PWP) is assumed to be 0.05 and 15 bar respectively (Hall et al., 1977) these, and other intermediate, tensions for soils of different textures can be plotted in the form of a graph (Fig. 8).

With reference to Fig. 8, as the season progresses and evapo-transpiration begins to exceed precipitation, soil moisture status changes from saturation or field capacity over the winter period to increasing moisture tension in the spring and summer. The curves of increasing soil moisture tension are approximately parallel and so provided that an indication of the moisture content at field capacity (upper curve, Fig. 9.) can be determined spatially across a given field, then an indication of soil variability in terms of texture and water-holding capacity can be obtained. In order to achieve this in practice, there is a requirement to obtain cost-effective data on soil moisture status when the soil profile can be considered to be at field capacity - i.e. after two days of drainage following saturation. This can be achieved in practice by EMI scanning.

EMI scans were conducted at Trent Field, Twelve Acres and Short Lane in February 1999, February 1999 and March 1998 respectively when the fields could reasonably be assumed to be at, or near, field capacity moisture status. Readings were taken on an approximate 10 by $24 \mathrm{~m}$ grid by 
walking along the field tramlines with a Geonics EM38 scanner. Maps produced from these scans are presented in Fig. 9.

The variation in EMI reflect the underlying soil variation determined using the mechanised minicore samples (Fig. 7). The potential of this method as a cost-effective surrogate for soil type, and hence the potential for using it as a practical basis for demarcating zones within fields that are appropriate for targeted soil sampling and subsequent agronomic management is explored in Part II of this paper.

\section{Variability of soil nutrients, $\mathrm{pH}$ and organic matter in trial fields}

For the purposes of this study, the nutrient status at specific locations within a field was required, and so grid sampling was conducted at four sites.

At the start of the project, the commercial practice for assessing spatial variations in soil nutrient status was to make observations at a rate of one per ha, i.e. on a $100 \mathrm{~m}$ grid. This was based on cost considerations rather than any technical reasons. For the purposes of this study, the sampling density was increased to approximately four observations per ha, i.e. approximately a $50 \mathrm{~m}$ grid. Again, cost considerations rather than strict technical reasoning limited the density. But, in the absence of technically based guidelines at the time, the increased density was considered to be nearer to a technical optimum. The appropriateness of this approach to nutrient management in the context of precision farming requires further investigation and this is addressed in Part II of this paper. Soil samples were taken by bulking a minimum of five sub-samples (one taken from the grid point and at least four from within a $5 \mathrm{~m}$ radius of the grid point) at the same locations on two dates; the first in the late autumn/winter and the second in spring. It is common commercial practice to sample in the autumn, however, as the concentration of certain elements (for example sulphur and potassium) could be affected by the winter period a second sampling was conducted in the spring. The dates, numbers and types of observations are summarised in Table 3. 
The spring observations included Total $\mathrm{N}$ and $\mathrm{NO}_{3}$ analyses and there were some variations in the list of elements analysed. Observations were made at two dates to investigate the stability of the measured levels with time.

According to a research review by Chalmers et al. (1999), the elements essential for plant growth can be classified according to the relative amounts required by the crop into:

(1) Major nutrients: nitrogen $(\mathrm{N})$, phosphorous $(\mathrm{P})$, potassium $(\mathrm{K})$, sulphur $(\mathrm{S})$, magnesium $(\mathrm{Mg})$, calcium $(\mathrm{Ca})$, and chlorine $(\mathrm{Cl})$

(2) Trace elements or micro-nutrients: boron $(B)$, copper $(\mathrm{Cu})$, iron $(\mathrm{Fe})$, manganese $(\mathrm{Mn})$, molybdenum (Mo) and zinc (Zn)

They conclude that deficiencies in $\mathrm{S}, \mathrm{Mg}, \mathrm{Cu}, \mathrm{Mn}$ and very rarely $\mathrm{Zn}$ can occur in cereal crops and are usually associated with specific soil types and, cereals are not susceptible to deficiencies in $\mathrm{B}, \mathrm{Cl}, \mathrm{Fe}$ and $\mathrm{Mo}$ under UK growing conditions. In this paper we will therefore concentrate on the potentially limiting elements other than $\mathrm{N}$ (discussed in depth in Welsh et al., 2001a \& b and Wood et al., 2001).

Yield-limiting levels of nutrient in soil analyses based on MAFF (2000) and from Chalmers et al. (1999) are summarised in Table 4. The latter research identifies some controversy over threshold levels below which cereal yields might be limiting

Scatterplots for $\mathrm{P}, \mathrm{K}, \mathrm{Mg}, \mathrm{Mn}, \mathrm{Cu}, \mathrm{Zn}$, and $\mathrm{S}$ in the four study fields are presented in Fig. 10. The ordinate is for the autumn/winter samples and the abscissa the spring samples. The one-to-one line helps to interpret the changes between sample dates. 


\section{Phosphorus (P)}

There are considerable increases in $\mathrm{P}$ between winter and spring observations in Far Sweetbrier and Onion Field. This could be explained by applications of $\mathrm{P}$ in fertiliser between the two sampling dates. Trent Field showed no increase and Twelve Acres showed a reduction. The spring levels were slightly below the limiting threshold in some points in Twelve Acres. Yield was not obviously lower at these locations. Far Sweetbrier, Onion Field and Trent Field were all above the threshold.

\section{Potassium (K)}

All fields were above the limiting threshold. Observations in Trent Field, Far Sweetbrier and Onion Field were generally scattered about the one-to-one line. Twelve Acres showed a decrease between the two sampling dates.

\section{Magnesium (Mg)}

All fields were above the limiting threshold. Observations were generally close to the one-toone line indicating stability of observations.

\section{Manganese (Mn)}

All fields were above the critical level. Parts of Onion Field were near the limit. Observations for Twelve Acres were systematically different in spring compared to winter observations. A difference in analytical procedure could be the reason. Otherwise the observations were generally stable between the two dates.

\section{Copper (Cu) and Zinc (Zn)}


All fields were above critical thresholds. Observations were stable between the two sampling dates.

\section{Sulphur (S)}

There were large differences between winter and spring measurements of $\mathrm{S}$ in the soil. Spring observations were considerably higher than the winter ones. This could be because of the known mobility of S or unreliability of the measurement procedure. Although some observations in all fields were below $20 \mathrm{mg} \mathrm{kg}^{-1}$, subsequent observations at the same sites from plant tissue analysis showed that $\mathrm{S}$ was not limiting in any of the trial fields.

Fig. 11 shows the $\mathrm{pH}$ status of the four experimental fields at the two sampling dates. In general, the $\mathrm{pH}$ values from the two dates are scattered about the one-to-one line indicating good consistency between sampling dates.

In Twelve Acres, the $\mathrm{pH}$ levels are all between 7.5 and 8.0 which is consistent with the proximity of limestone parent material to the soil surface. There were much larger variations in the other three fields. In Trent Field the lower values of $\mathrm{pH}$ corresponded to the region of the field with the deeper subsoils where there was less mixing by tillage of chalk with the surface soil. In the same region of the field, there were indications of poor crop development which could be seen by field walking and on aerial digital photographs. Subsequently, $\mathrm{pH}$ levels as low as 5.1 were observed in soil samples taken from within this region. This indicated the need for liming on the deficient part of the field which was a surprising finding considering the proximity of chalk to the surface. This prompted the farmer to investigate other parts of his farm with similar soil depths and it transpired that these also required targeted liming. In Far Sweetbrier, there were four observation sites with $\mathrm{pH}$ values below 6.5; two of these were below 5.0. These four sites corresponded to the 
lowest yielding areas in the field. In Onion Field, pH levels were below 6.0 at one location which corresponded with a depression in yield

Fig. 12 shows the Organic Matter status in the trial fields at the two sampling dates.

There is considerable scatter about the one-to-one line but this may reflect the precision of the methodology since the scatter is unbiased. All observations were equal to or above $2.5 \%$ indicating that levels were within accepted norms for the soils concerned.

\section{Conclusions}

Conventional methods, such as hand auger surveys at $100 \mathrm{~m}$ grid points and the excavation of soil profile pits, for sampling soil in order to measure spatial variation in soil factors are time consuming and this places a practical and economic limitation on the number of observations possible in any given field. Whilst both methods provide information that can lead to the identification of variation in soil type at specific locations, the data sets are too sparse to enable accurate soil type boundaries to be demarcated with confidence at resolutions below $100 \mathrm{~m}$ unless a denser sampling regime is adopted for targeted areas.

Soil profile pits provide detailed information on soil physical properties, however, it is important to adopt an appropriate rationale for identifying pit locations that will enable the data to be optimised in terms of characterising the different soil types within a field whilst limiting the number of pits excavated. This can be achieved by referring to the following maps and locating the pits accordingly: 
(1) Historic yield maps - 1 pit in high, medium and low yielding areas.

(2) Crop canopy density inferred from aerial digital photography in May - 1 pit in high, medium and low yielding areas.

(3) Soil maps from hand auger surveys - 1 pit in each dominant soil type.

This approach resulted in the need for approximately nine pits per field for the sites adopted as case studies during this project, however, in the context of a commercial farming situation, this could be reduced to four to five pits with little loss of data. Provided that the exposed soil profiles are photographed, then the excavations can be viewed as a long term investment and the costs offset as such (Godwin and Miller, 2001).

The resolution of soil boundary locations can be increased by using mechanised soil coring devices that are capable of achieving high sampling densities, however, this approach is limited by the time required to analyse the soil cores produced.

Electromagnetic induction (EMI) scans, conducted when soil is at or near field capacity, have the potential to provide a cost-effective, data rich, surrogate for measures of soil physical properties. The determination of spatial variation in soil type within a field, whilst remaining within financial and economic constraints, could be achieved by using EMI to guide the targeting of locations for conventional soil sampling thereby limiting the number of observations required to characterise the field. Whilst EMI scans of soil were conducted at or near field capacity during this study in order to provide indications of variation in soil physical properties, it may be valid to scan soil in drier conditions provided that the crop canopy is relatively uniform. This is because the relationship between soil water content (a dominant factor influencing EMI) and soil texture remains approximately parallel for increasing soil water tensions. 
The results of nutrient analyses on soil sampled on an approximate $50 \mathrm{~m}$ grid has emphasised the need to address variations in critical factors such as $\mathrm{pH}$ at specific locations within a field where nutrient levels are below established limits. Whilst the sampling density adopted during this was four times greater than common commercial practice, there is a need to develop protocols for targeting sampling in order to reduce costs.

The development of sampling strategies, procedures for analysing the relationships between soil and crop variation, and procedures for identifying management zones within fields is addressed in Part II of this paper.

\section{Acknowledgements}

The authors would like to thank the sponsors of this work, Home-Grown Cereals Authority, Hydro Agri and AGCO Ltd. for their support, and the contributions made by their collaborators, Arable Research Centres and Shuttleworth Farms. We would also like to thank Dr. David Pullen and Dr. Nicola Cosser for their assistance in developing the research programme. Grateful thanks are expressed to five farmers, Mr Eayrs, Mr J Hart, Mr R Dines, Mr F Wilson and Mr B Welti, for supplying the field sites for these investigations. 


\section{References}

Avery B W (1987). Soil Survey Methods: A Review. Soil Survey Technical Monograph No 18, Soil Survey and Land Research Centre, Cranfield University, Silsoe, UK

Cannell R Q; Davies D B; Mackney D; Pidgeon J D (1978). The suitability of soils for sequential direct drilling of combine-harvested crops in Britain - a provisional classification. Outlook on Agriculture, 9(6), pp. 303-316

Chalmers G; Sinclair A H; Carver M (1999). Nutrients other than nitrogen, phosphorous and potassium (NPK) for cereals. Home-Grown Cereals Authority Research Review, No. 41, London N1 9NG, UK

Clayden B; Hollis J M (1984). Criteria for differentiating soil series. Soil Survey Technical Monograph No 17, Soil Survey of England and Wales, Harpenden

Dalgaard M; Have H; Nehmdahl H (2001). Soil clay mapping by measurement of electromagnetic conductivity. Proc. $3^{\text {rd }}$ European Conf. on Precision Agriculture, Montpellier, France

Earl R; Wheeler P N; Blackmore B S; Godwin R J (1996). Precision farming - the management of variability. Landwards, 51(4), pp 18-23

Food and Agriculture Organisation of the United Nations (1998). World reference base for soil resources, world soil resources reports, 84, Rome

Godwin R J; Miller P C H (2001). A Review of Technologies for Mapping within Field Variability, Precision Agriculture (in press)

Hall D G M; Reeve M J; Thomasson A J; Wright V F (1977). Water retention, porosity and density of field soils. Soil Survey Technical Monograph No 9, Soil Survey of England and Wales, Harpenden, UK 
James I T; Waine T W; Bradley R I; Godwin R J; Taylor J C (2000). A comparison between traditional methods and scanning for determining soil textural boundaries. Paper No. 00-PA014, AgEng2000, Warwick, UK

Jaynes D B; Colvin T S; Ambuel J (1994). Yield mapping by electromagnetic induction. Proc. $2^{\text {nd }}$ International. Conference on Precision Agriculture, Minneapolis, USA

Kachanoski R G; Gregorich E G; VanWesenbeeck I J (1988). Estimating spatial variations of soil water content using non-contacting electromagnetic inductive methods", Canadian Journal of Soil Science, 68, pp. 715-722

Lark E M; Bolan H C; Mayr T; Bradley R I; Burton R G O; Dampney P M R (1998). The development of cost-effective methods for analysing soil information to define crop management zones. Home-Grown Cereals Authority Project Report, No. 171, London N1 9NG, UK

Ministry of Agriculture Fisheries and Food (2000). Fertiliser recommendations for agricultural and horticultural crops (RB209). $7^{\text {th }}$ ed., Stationary Office, London, UK

National Soil Resources Institute (NSRI) (2001). A guide to better soil structure. Cranfield University at Silsoe, Bedforshire

Rhoades J D; Ratts P A C; Prather R S (1976). Effects of liquid-phase electrical conductivity, water content and surface conductivity on bulk soil electrical conductivity. Soil Science Society of America Journal, 40, pp. 651-665

Rhoades J D; Corwin D L (1981). Determining soil electrical conductivity-depth relations using an inductive electromagnetic soil conductivity meter. Soil Science Society of America Journal, 45, pp. 255-260

USDA Soil Survey Staff (1999) Soil Taxonomy: a basic system of soil classification for making and interpreting soil surveys. $2^{\text {nd }}$ ed., NRCS, Washington, USA 
Waine T W (1999). Non-invasive soil property measurement for precision farming. EngD Thesis, Cranfield University, Silsoe, Bedford MK45 4DT, UK

Waine T W; Blackmore B S; Godwin R J (2000). Mapping available water content and estimating soil textural class using electro-magnetic induction. Paper No. 00-SW-044, AgEng2000, Warwick, UK

Welsh J P; Wood G A; Godwin R J; Taylor J C; Earl R; Blackmore B S (2001). Developing strategies for spatially variable nitrogen application in cereals I: Winter Barley. Submitted to Precision Agriculture

Welsh J P; Wood G A; Godwin R J; Taylor J C; Earl R; Blackmore B S (2001). Developing strategies for spatially variable nitrogen application in cereals II: Wheat. Submitted to Precision Agriculture

Williams B G; Hoey D (1987). The use of electromagnetic induction to detect the spatial variability of the salt and clay contents of soils. Australian Journal of Soil Research, 25, pp. $21-27$

Wood G A; Taylor J C; Thomas G (1998). Developing calibration techniques to map crop variation and yield potential using remote sensing. Proceedings 12th Int. Conf. on Precision Agriculture, St. Paul, Minnesota, USA

Wood G A; Taylor J C; Godwin R J; Welsh J P (2001). Site-specific management of canopy size for optimising yield potential by remote sensing. Proceedings of the $3^{\text {rd }}$ European Conference on Precision Agriculture, Montpellier, France

Wood G A; Taylor J C; Godwin R J (2001). Calibration Methodology for Mapping Within-Field Crop Variability using Remote Sensing. Submitted to Precision Agriculture 
Figures for:

Soil Factors and their Influence on Within-Field Crop Variability

I: Field Observation of Soil Variation

R. Earl ${ }^{1}$; J.C. Taylor ${ }^{1}$; G.A. Wood ${ }^{1}$; I. Bradley, I.T. James ${ }^{1}$, T. Waine ${ }^{1}$; J.P. Welsh ${ }^{1}$;

R.J. Godwin ${ }^{1}$ S.M. Knight ${ }^{2}$ 
Table 1

Methods for measuring soil variability

Method

Auger surveys

Profile pits

Minicore soil samples

Electro-magnetic inductance

Nutrient sampling
Soil factor(s)

Rapid assessment of the spatial distribution of soil type (texture) across a field.

Targeted excavations to establish soil type and soil structure/packing state at specific locations within a field. Rapid assessment of the spatial distribution of soil type and depth across a field.

Non-invasive assessment of variation in electrical conductivity across a field which provides and indication of changes in soil moisture content, soil salinity ${ }^{1}$ and soil texture $^{2}$.

Sampling soil for subsequent laboratory analysis to establish nutrient and $\mathrm{pH}$ status.

${ }^{1}$ Rhoades et al. (1976); ${ }^{2}$ Waine et al. (2000) 


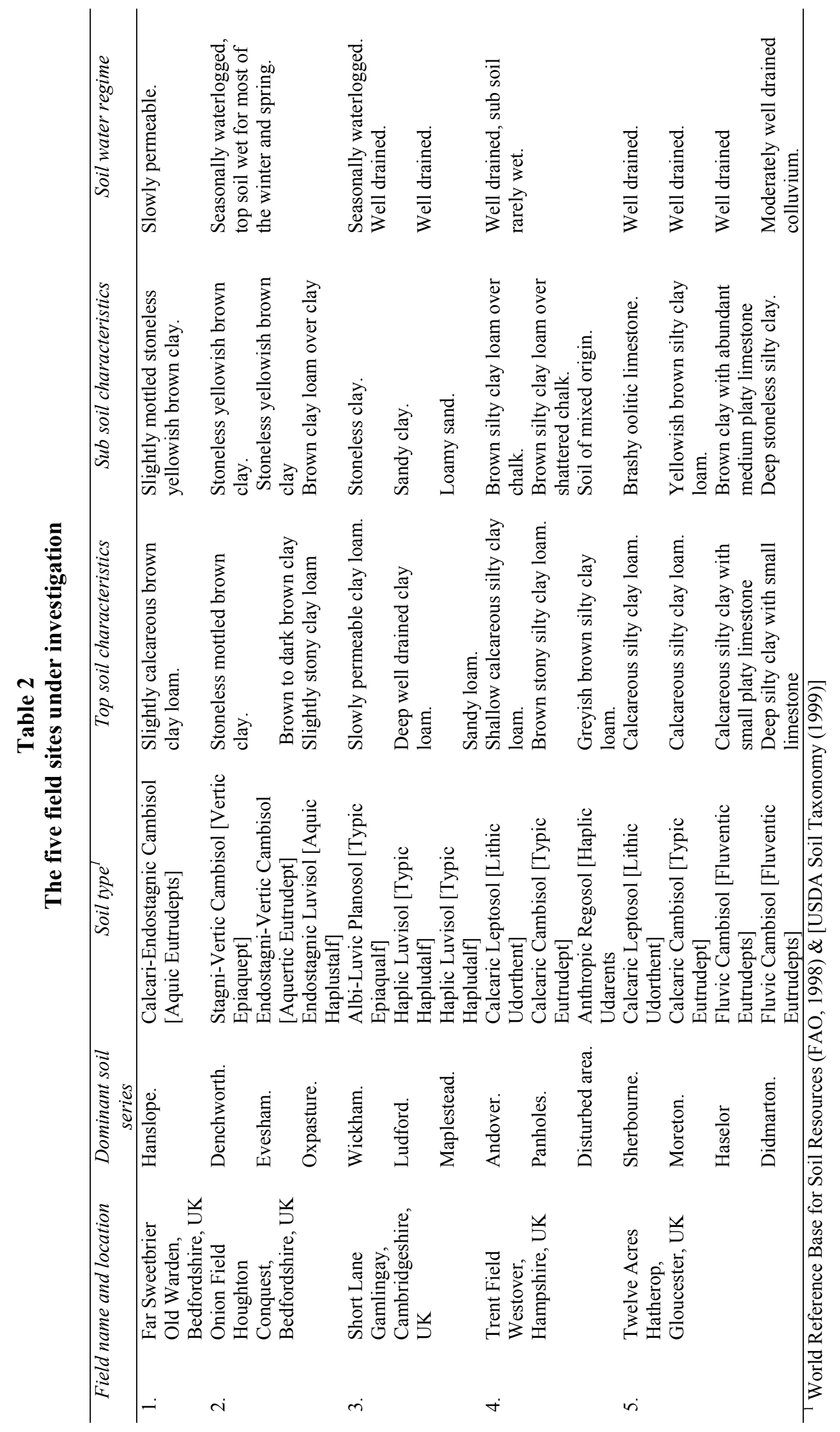




\section{Table 3}

Summary of grid soil sampling for soil analysis in Trent Field, Twelve Acres, Far Sweetbrier and Onion Field.

\begin{tabular}{|c|c|c|}
\hline Field & Date 1 & Date 2 \\
\hline \multirow[t]{4}{*}{ Trent Field } & $4 \operatorname{Dec} 96$ & 30 April 97 \\
\hline & $\mathrm{pH}$, Organic Matter $\mathrm{P}, \mathrm{K}, \mathrm{Ca}, \mathrm{Mg}$, & $\mathrm{pH}$, Organic Matter, $\mathrm{P}, \mathrm{K}, \mathrm{Mg}$, \\
\hline & $\mathrm{Mn}, \mathrm{Fe}, \mathrm{Zn}, \mathrm{Cu}, \mathrm{B}, \mathrm{Mo}, \mathrm{S}$ & $\mathrm{Mn}, \mathrm{Cu}, \mathrm{Zn}, \mathrm{S}, \mathrm{N}$ Total, $\mathrm{NO}_{3}$ \\
\hline & 28 observations & 27 observations \\
\hline \multirow[t]{4}{*}{ Twelve Acres } & 14 Jan 97 & 25 April 97 \\
\hline & $\mathrm{pH}, \mathrm{P}, \mathrm{K}, \mathrm{Ca}, \mathrm{Mg}, \mathrm{Mn}, \mathrm{Fe}, \mathrm{Zn}$, & $\mathrm{pH}$, Organic Matter, $\mathrm{P}, \mathrm{K}, \mathrm{Mg}$, \\
\hline & $\mathrm{Cu}, \mathrm{NH} 3, \mathrm{NO}_{3}$, Total $\mathrm{N}$ & $\mathrm{Mn}, \mathrm{Cu}, \mathrm{Zn}, \mathrm{S}, \mathrm{N}$ Total, $\mathrm{NO}_{3}$ \\
\hline & 29 observations & 29 observations \\
\hline \multirow[t]{4}{*}{ Far Sweetbrier } & 25 Nov 96 & 29 April 97 \\
\hline & $\mathrm{pH}$, Organic Matter $\mathrm{P}, \mathrm{K}, \mathrm{Ca}, \mathrm{Mg}$, & $\mathrm{pH}$, Organic Matter, $\mathrm{P}, \mathrm{K}, \mathrm{Mg}$, \\
\hline & $\mathrm{Mn}, \mathrm{Fe}, \mathrm{Zn}, \mathrm{Cu}, \mathrm{B}, \mathrm{Mo}, \mathrm{S}$ & $\mathrm{Mn}, \mathrm{Cu}, \mathrm{Zn}, \mathrm{S}, \mathrm{N}$ Total, $\mathrm{NO}_{3}$ \\
\hline & 26 observations & 26 observations \\
\hline \multirow[t]{4}{*}{ Onion Field } & 25 Nov 96 & 29 April 97 \\
\hline & $\mathrm{pH}$, Organic Matter $\mathrm{P}, \mathrm{K}, \mathrm{Ca}, \mathrm{Mg}$, & $\mathrm{pH}$, Organic Matter, $\mathrm{P}, \mathrm{K}, \mathrm{Mg}$, \\
\hline & $\mathrm{Mn}, \mathrm{Fe}, \mathrm{Zn}, \mathrm{Cu}, \mathrm{B}, \mathrm{Mo}, \mathrm{S}$ & $\mathrm{Mn}, \mathrm{Cu}, \mathrm{Zn}, \mathrm{S}, \mathrm{N}$ Total, $\mathrm{NO}_{3}$ \\
\hline & 40 observations & 40 observations \\
\hline
\end{tabular}


Table 4.

Summary of limiting levels of soil nutrients

\begin{tabular}{crl}
\hline Nutrient & $\begin{array}{c}\text { Level } \\
\left(\mathrm{ml} \mathrm{l}^{-1}\right)\end{array}$ & \multicolumn{1}{c}{ Comments } \\
\hline $\mathrm{P}$ & 16.0 & \\
$\mathrm{~K}$ & 120.0 & \\
$\mathrm{Mg}$ & 25.0 & Index 0 \\
$\mathrm{Mn}$ & 20.0 & Treated by foliar applications. Soil analysis unreliable \\
$\mathrm{Cu}$ & 1.6 & \\
$\mathrm{Zn}$ & 1.0 & \\
$\mathrm{~S}$ & 10.0 & Measurement unreliable \\
\hline
\end{tabular}




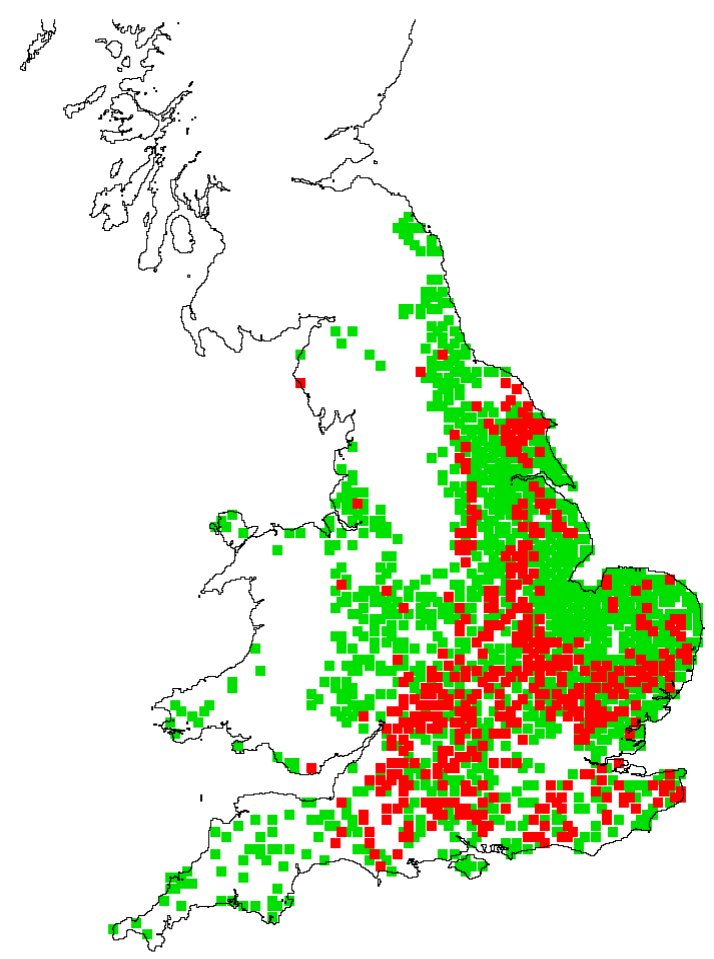

$\square \quad$ Soils in arable cultivation similar to those at the field sites $\square \quad$ Other arable areas in England and Wales

\section{Cranfield University: Soil Survey and Land Research Centre}

Fig. 1. Distribution of soils in England and Wales that are similar to those present at the field sites.

Greyscale possible, but preferably colour print and online 


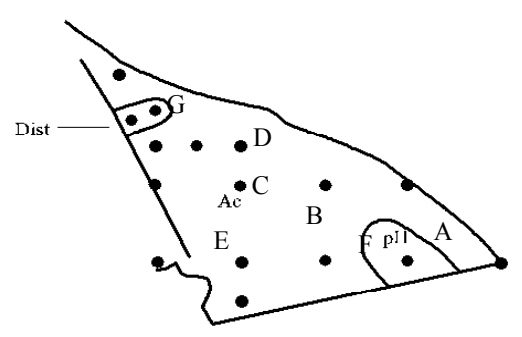

Trent Field
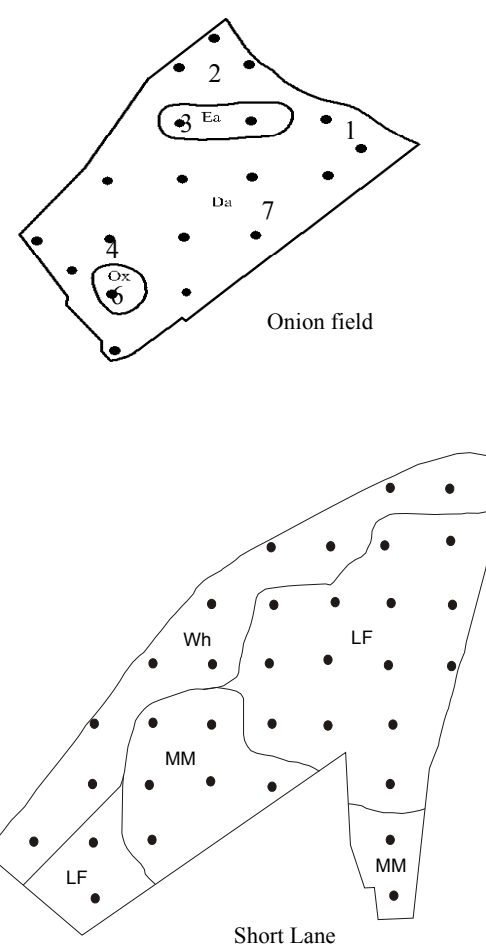
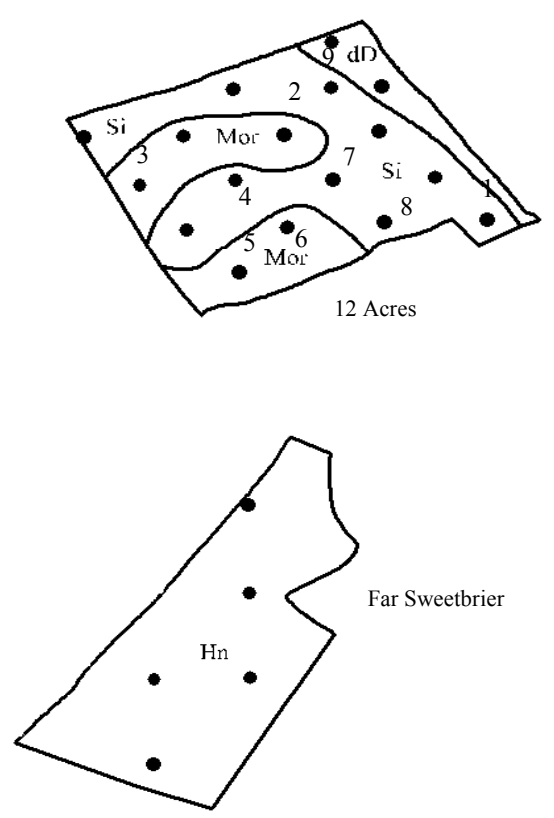

\begin{tabular}{ll}
\hline Soil series/factor & Key \\
\hline Andover & $\mathrm{Ac}$ \\
Panholes & $\mathrm{PH}$ \\
Disturbed area & $\mathrm{Dist}$ \\
Sherbourne & $\mathrm{Si}$ \\
Moreton & $\mathrm{Mor}$ \\
Didmarton & $\mathrm{DD}$ \\
Haselor & $\mathrm{Hb}$ \\
Denchworth & $\mathrm{Da}$ \\
Evesham & $\mathrm{Ea}$ \\
Oxpasture & $\mathrm{Ox}$ \\
Hanslope & $\mathrm{Hn}$ \\
Wickham & $\mathrm{Wh}$ \\
Ludford & $\mathrm{LF}$ \\
Maplestead & $\mathrm{MM}$ \\
Profile pit location & 6 or F \\
\hline
\end{tabular}

Fig. 2. Soil Maps produced from auger sampling at $100 \mathrm{~m}$ grid spacing. 

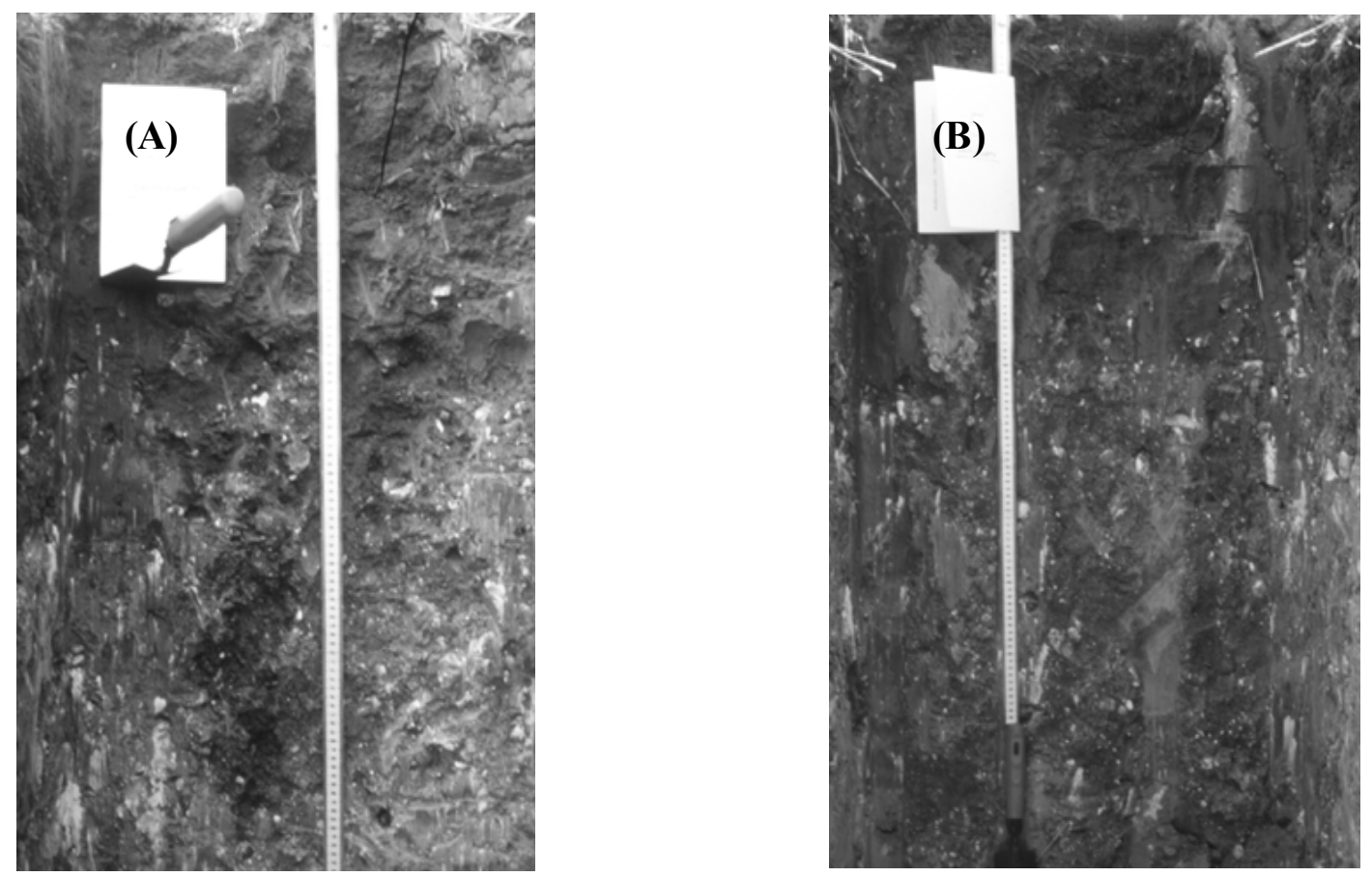

Fig. 3. Soil profile pits in Far Sweetbrier showing (A) and (B) Hanslope soil series. 


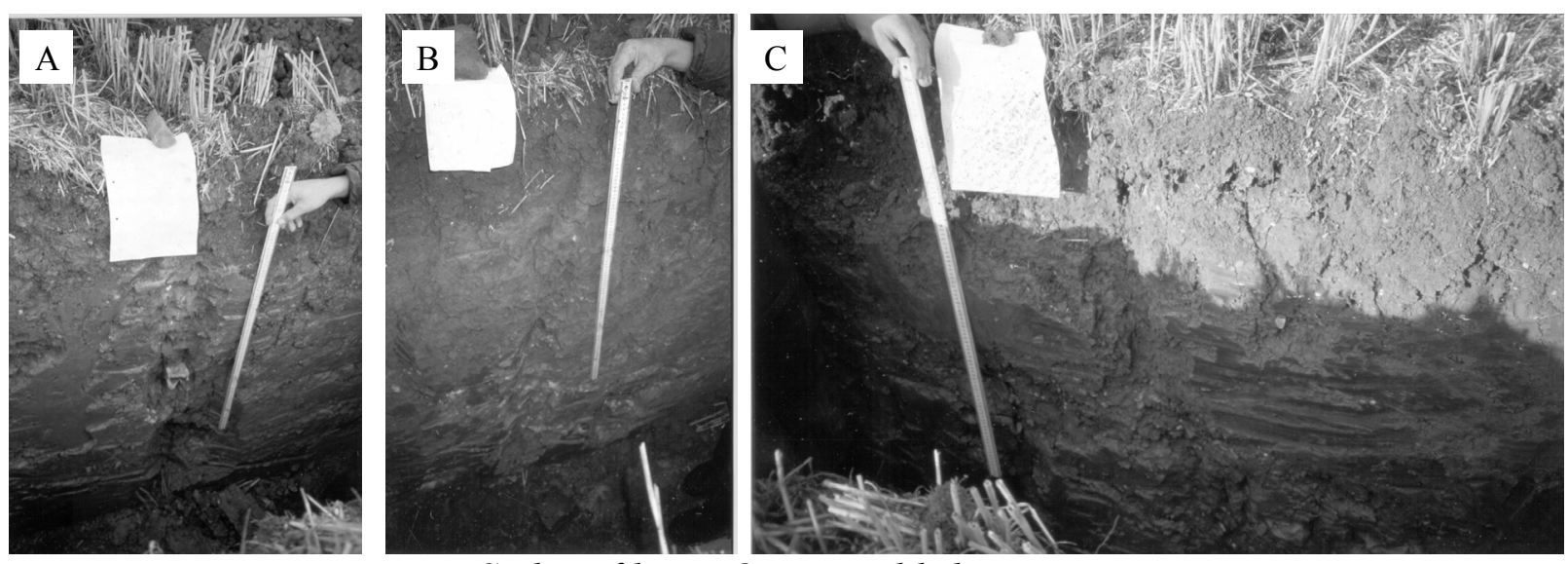

Fig. 4. Soil profiles in Onion Field showing

(A), Evesham; (B), Denchworth; (C), Oxpasture soil series 

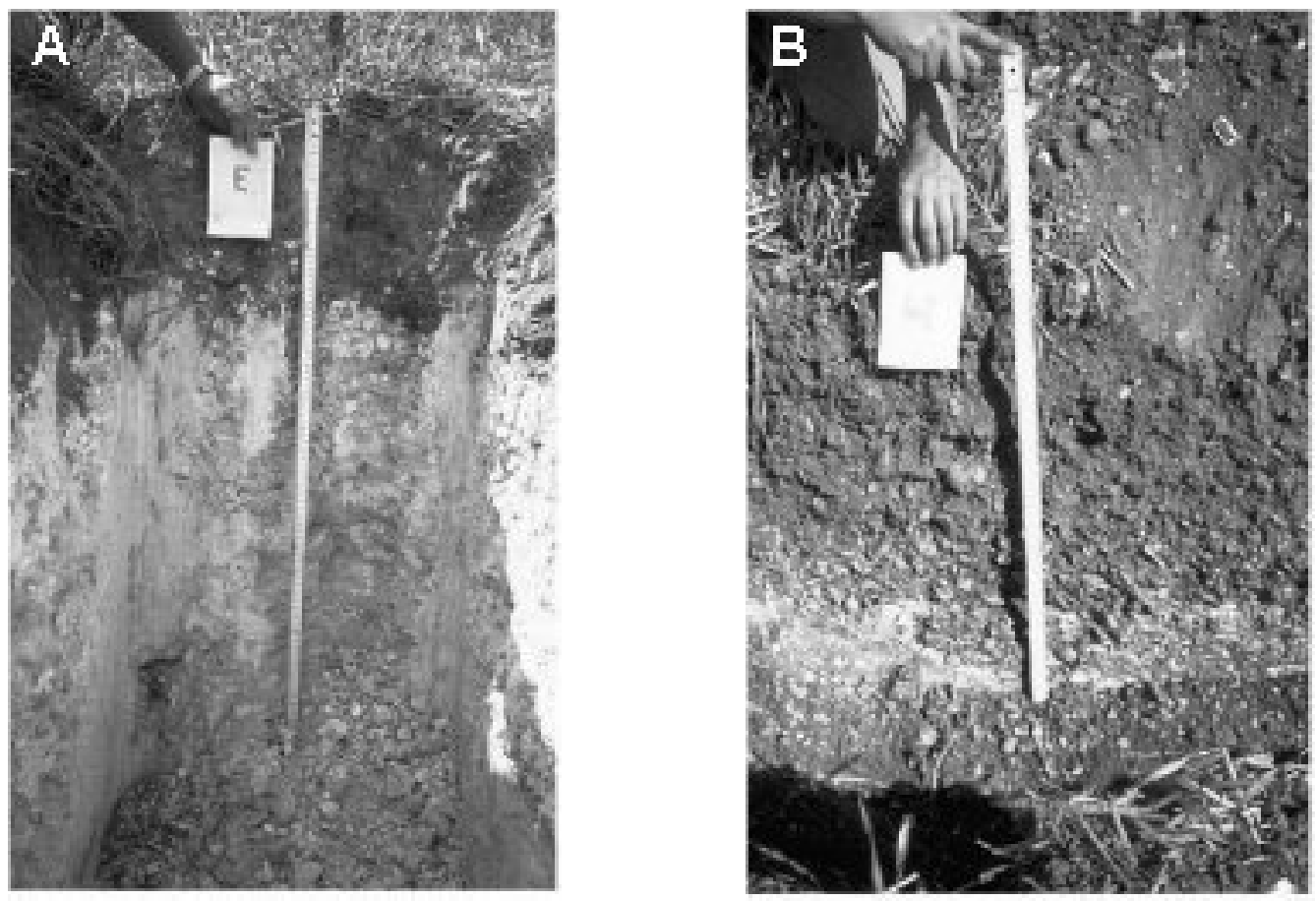

Fig. 5. Soil profile pits for Trent Field showing (A), Andover;(B), Panholes soil series 

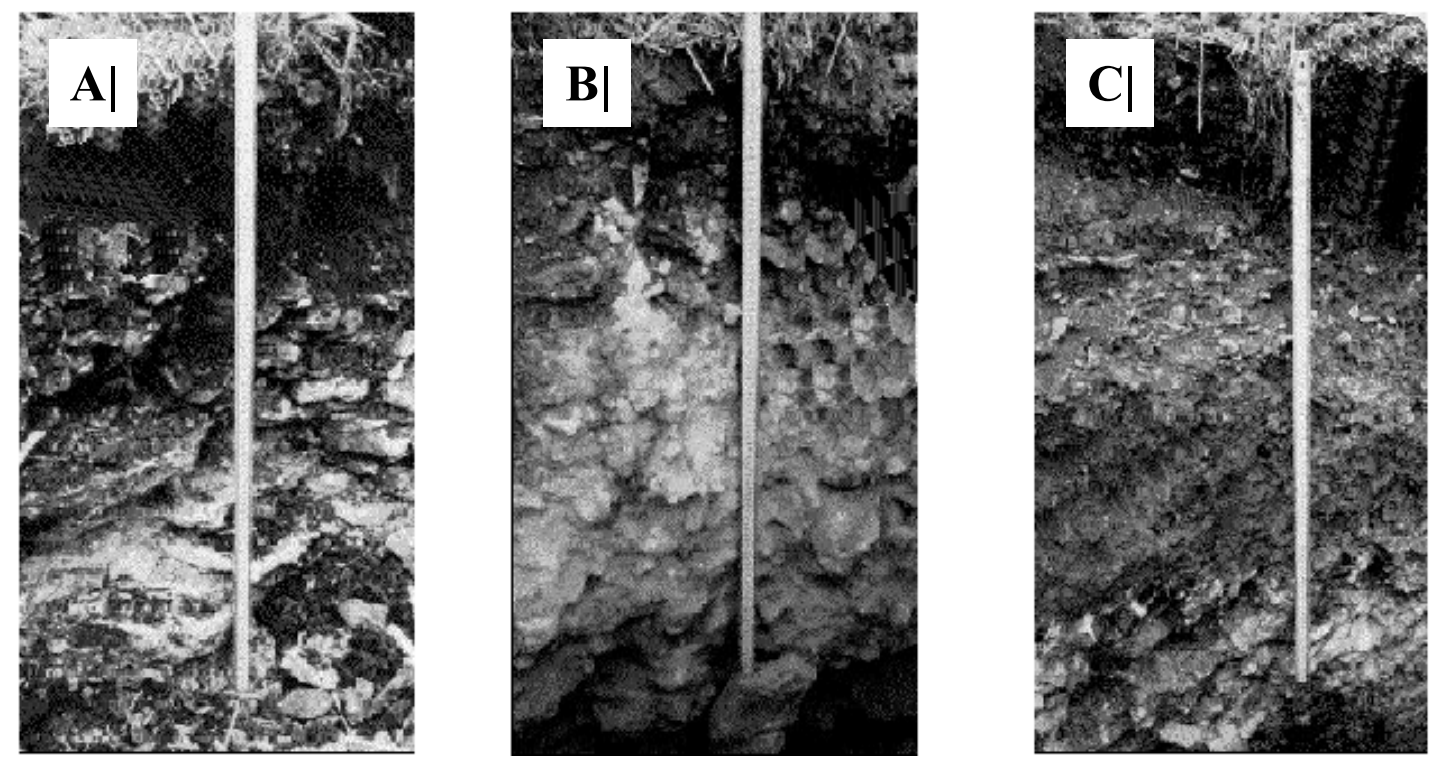

Fig. 6. Soil profile pits in Twelve Acres showing (A), Moreton; (B), Sherborne; (C), Didmarton soil series 

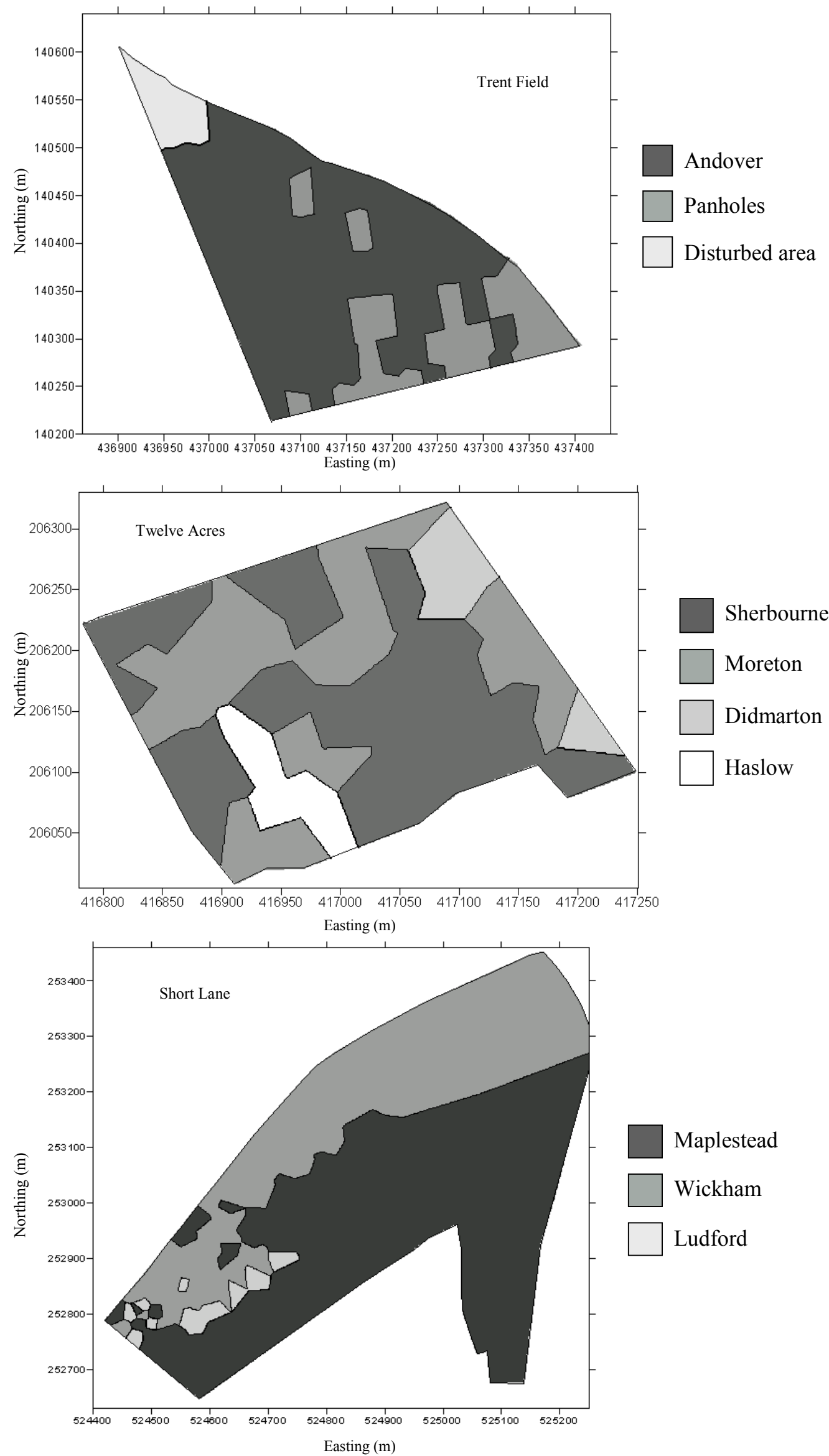

Fig. 7. Soil maps produced from mechanised core sampler. 


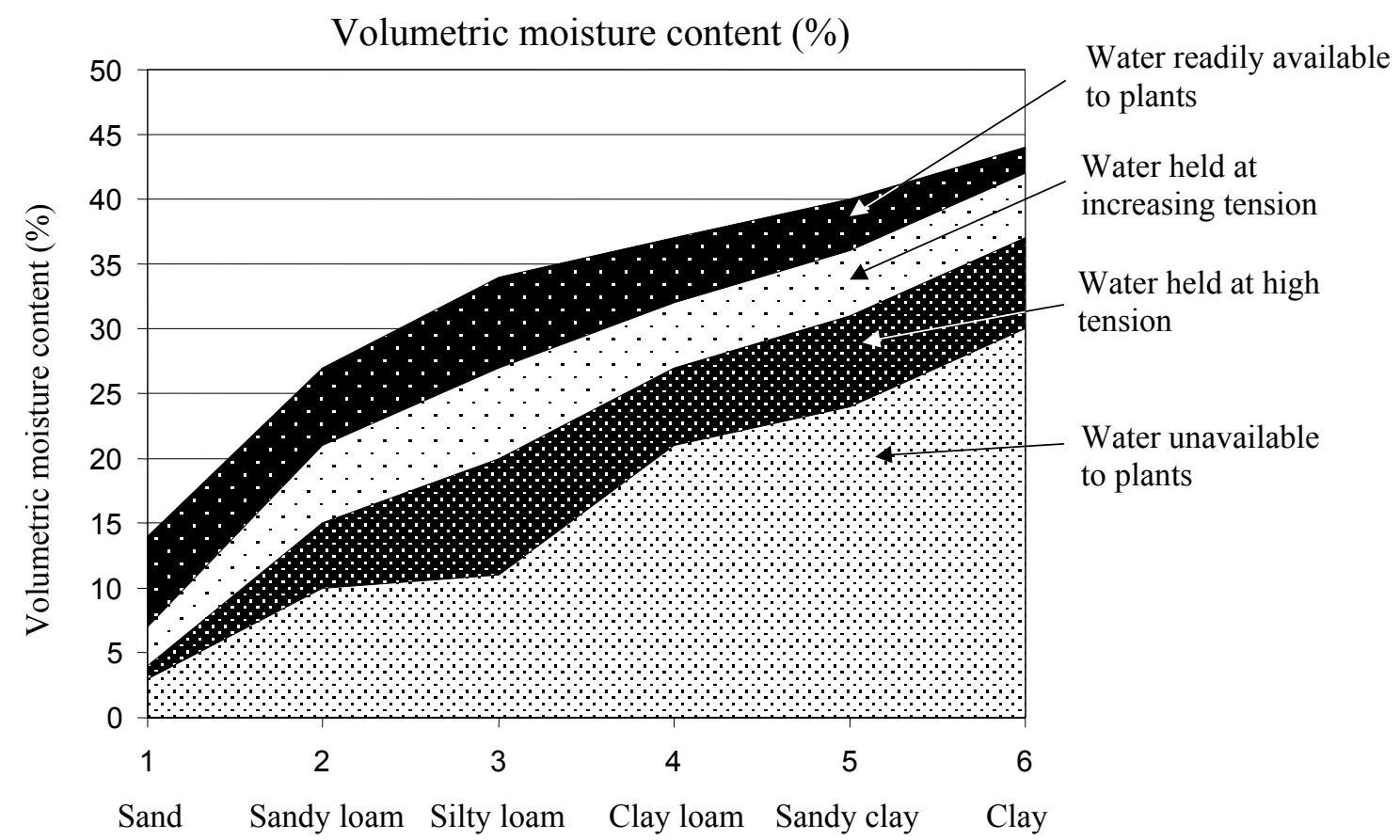

Soil texture

Fig. 8. The relationship between volumetric moisture content at various moisture tensions and the texture of UK soils (data taken from Hall et al., 1977): $\mathbf{0}, 0.05$ bar; ๑, 0.4 bar; $\mathbf{6}, 2.0$ bar; . 15 bar 

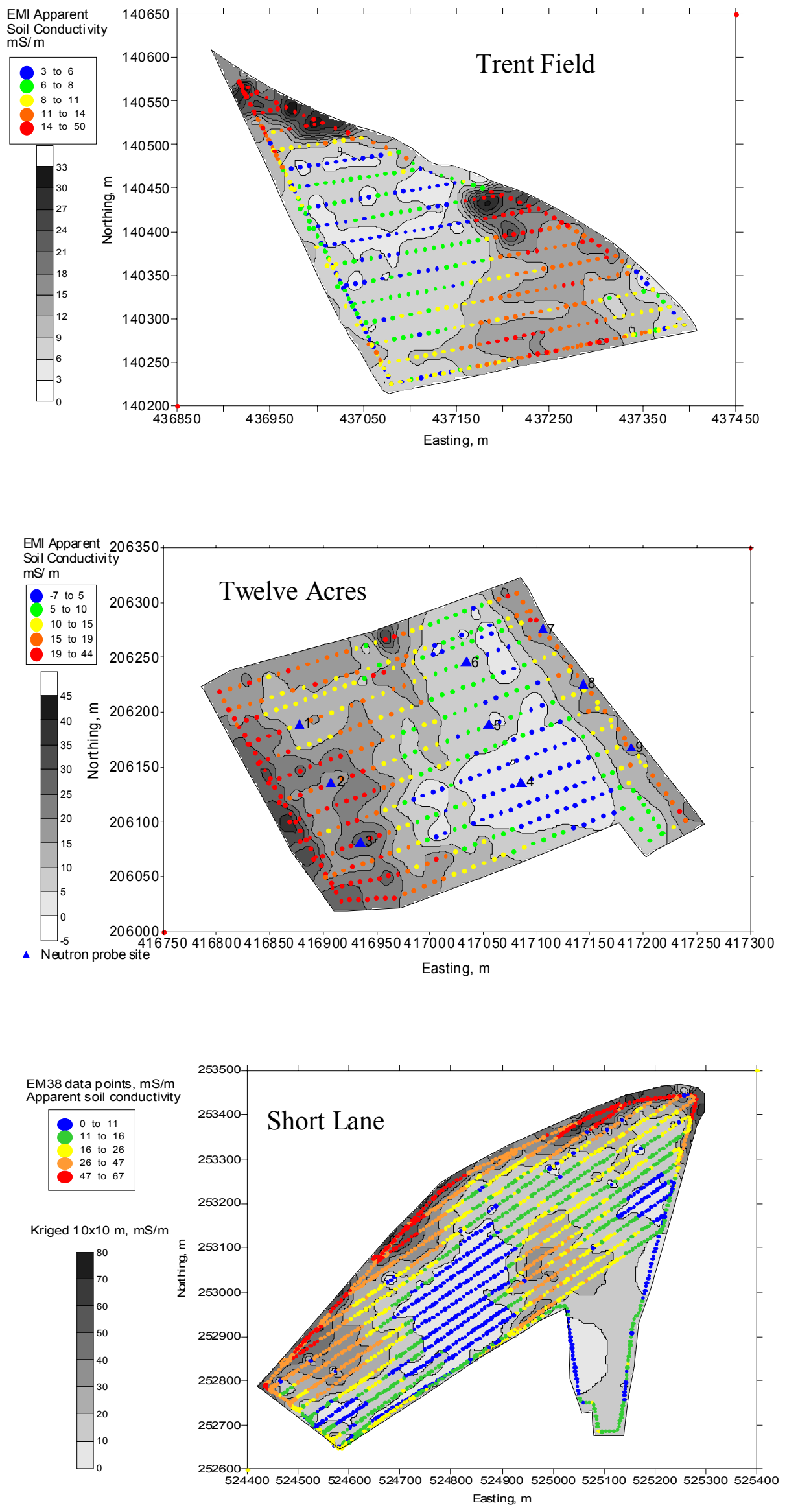

Fig. 9. Maps of variation in electromagnetic inductance in three fields 

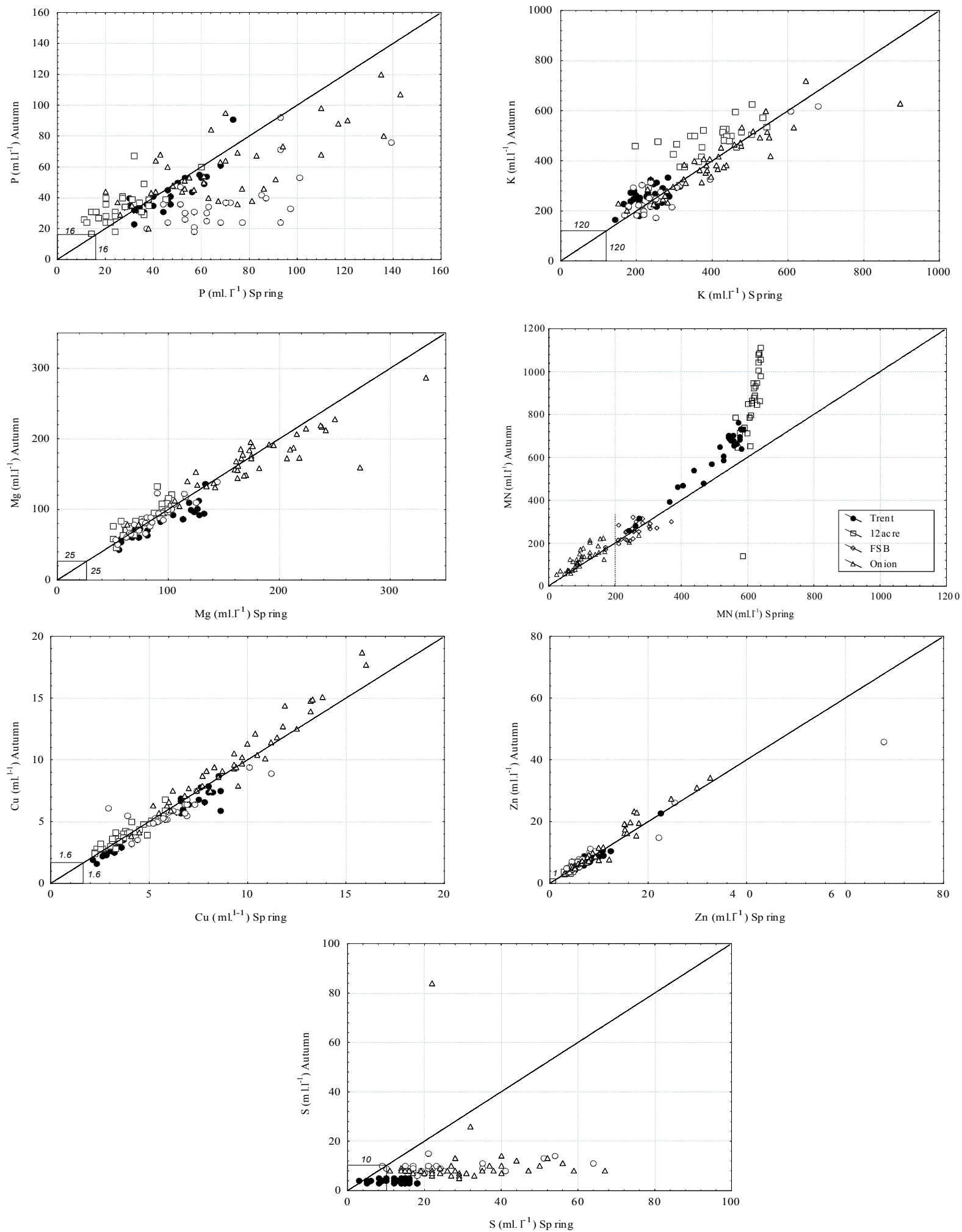

Fig. 10. Scatter plots for $P, K, M g, M n, C u, Z n$ and $S$ nutrient levels at four field sites: ○, Trent; $\square$, Twelve Acre; O, Far Sweetbrier; $\triangle$, Onion 


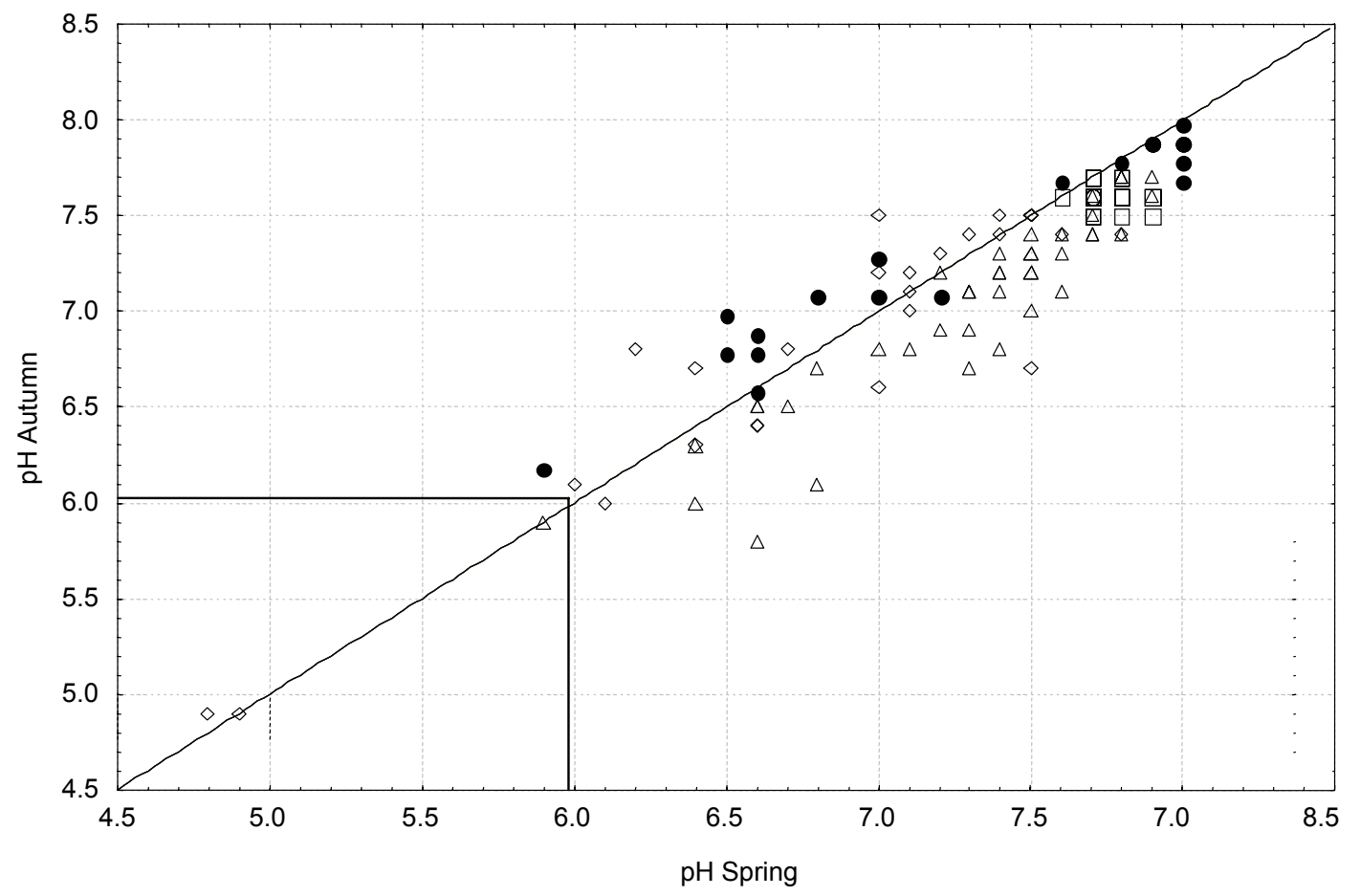

Fig. 11. Scatter plots showing $p H$ status in the autumn and spring at four field sites:

-, Trent; $\square$, Twelve Acre; O, Far Sweetbrier; $\triangle$, Onion 


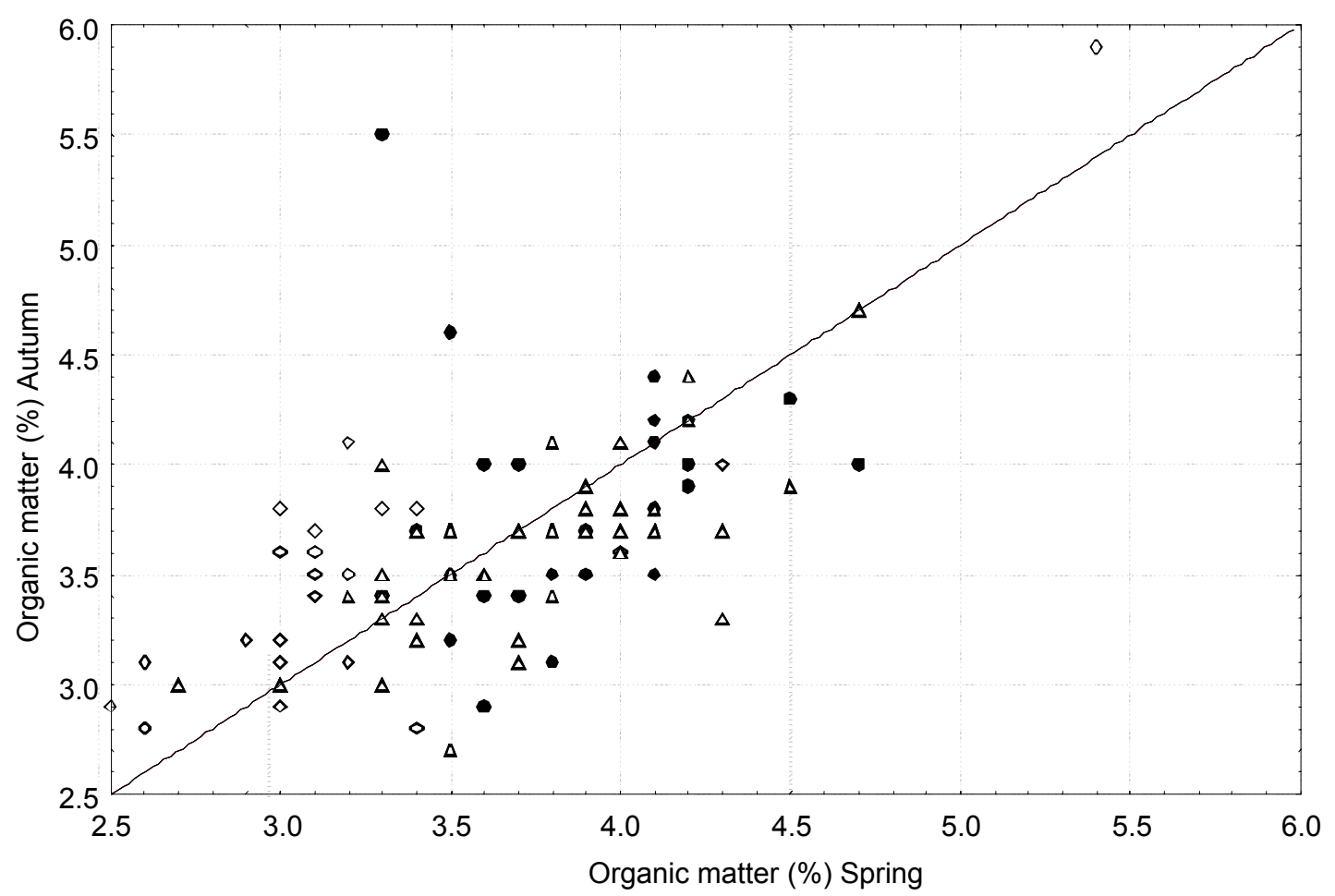

Fig. 12. Scatter plots showing the organic matter status in the autumn and spring at four field sites: - Trent; $\square$, Twelve Acre; O, Far Sweetbrier; $\triangle$, Onion 